Género, biografia e historia oral o de cómo contar la vida de Ana Maria Villareal de Santucho

Andrea Andújar - Débora D’Antonio - Mónica Gatica

Anuario No 34 / ISSN 1853-8835 / 2021

http://anuariodehistoria.unr.edu.ar/ojs/index.php/Anuario/index

\title{
Género, biografia e historia oral o de cómo contar la vida de Ana Maria Villareal de Santucho
}

\section{Gender, biography and oral history or how to tell the life of Ana Maria Villarreal de Santucho}

\author{
ANDREA ANDÚJAR \\ Instituto de Investigaciones de Estudios de Género; \\ Universidad de Buenos Aires; \\ Consejo Nacional de Investigaciones Científicas y Técnicas (Argentina) \\ andreaandujar@gmail.com \\ DÉBORA D`ANTONIO \\ Instituto de Investigaciones de Estudios de Género; \\ Universidad de Buenos Aires; \\ Consejo Nacional de Investigaciones Científicas y Técnicas (Argentina) \\ deboradantonio@hotmail.com
}

MÓNICA GATICA

Instituto de Investigaciones Históricas y Sociales;

Facultad de Humanidades y Ciencias Sociales; Universidad Nacional de la Patagonia (Argentina) monicagracielagatica@yahoo.com.ar

RESUMEN

Este trabajo se propone reconstruir la biografia de Ana Maria Villarreal de Santucho, militante del Partido Revolucionario de los Trabajadores-Ejército Revolucionario del Pueblo y esposa de su líder máximo Mario Roberto Santucho entre 1960 y 1972, cuando fue asesinada junto con otrxs quince militantes en la Base Aeronaval Almirante Zar, dependencia de la Armada argentina cercana a la ciudad de Trelew. Para ello, este estudio recurre a un acervo documental variado conformado por entrevistas, cartas personales, fotografias, expedientes judiciales, documentos politicos, prensa comercial y político partidaria.

Palabras clave: biografia; género; militancia revolucionaria; Argentina. 


\begin{abstract}
This article purposes to reconstruct the biography of Ana Maria Villarreal de Santucho, a militant of the Partido Revolucionario de los Trabajadores- Ejército Revolucionario del Pueblo and wife of its maximum leader, Mario Roberto Santucho, between 1960 and 1972, when she was assassinated along with others fifteen militants at the Almirante Zar Naval Air Base, a dependency of the Argentine Navy near the city of Trelew. To do this, this study recurs to a varied documentary heritage made up of interviews, personal letters, photographs, court files, political documents, commercial and political press.
\end{abstract}

Keywords: biography; gender; revolutionary militancy; Argentina.

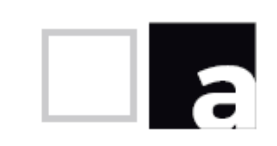

\title{
Introducción
}

Este trabajo se propone reconstruir la biografia de Ana María Villarreal de Santucho, una mujer que se incorporó a la vida política, y en especial a la lucha armada, para hacer la revolución socialista en la Argentina. Fue apodada cariñosamente Sayonara o Sayo debido a sus ojos rasgados y a su parecido con Miiko Taka, la actriz protagónica de una película norteamericana estrenada en 1957. ${ }^{1}$ Valiéndonos del uso de la historia oral, la historia reciente y sus cruces con los estudios de género como estrategia teórico-metodológica, buscamos los nexos entre los acontecimientos vividos por ella, su propia agencia política y la trama en la que intervino. Asumimos que ese análisis es una puerta de entrada valiosa para lograr una comprensión más acabada de las conflictivas décadas del sesenta y setenta a partir del examen de las experiencias de una generación de mujeres comprometidas con las transformaciones sociales radicales. Procuramos, además, superar los desafios conceptuales e historiográficos que, al traspasar los relatos meramente fácticos, se presentan a la hora de retomar las diversas memorias existentes sobre una militante cuya figura se destacó por su actividad en el Partido Revolucionario de los Trabajadores-Ejército Revolucionario del Pueblo (PRT-ERP).

1 Se trataba de Sayonara, film dirigido por Joshua Logan y co-protagonizado por Marlon Brando. 
En los últimos años asistimos a un auge del método biográfico que responde, en buena medida, a la revalorización del sujeto social (tanto individual como colectivo) y de las implicancias de su agencia en el pasado histórico. En diálogo con sus aportes y despojando a Ana María Villarreal de Santucho de la condición de representante arquetípico de un grupo, esta reconstrucción pretende indagar múltiples dimensiones para componer una imagen más vívida y cotidiana de su trayectoria, ubicada -podríamos decir- a ras del piso. Para ello seguimos sus pistas a lo largo de una crianza localizada en una provincia norteña, dentro de una trama familiar sin sobresaltos económicos que le permitió concluir sus estudios escolares animándola a explorar el mundo de las artes. Ana dejó la casa de infancia para ir a la universidad; obtuvo un título, militó, se casó y fue madre de tres hijas en ese matrimonio. Esa trayectoria no fue lineal, sino plena de contradicciones que trasuntan también en este escrito.

Nos movemos aquí entre tensiones que retoman o no escapan, de algún modo, a las propias de las vicisitudes de la vida de Ana. Así, la reconocemos en sus singularidades, aunque compartiendo pautas, valores y prácticas de otras mujeres de su generación y, como se ha dicho, del contexto en que le tocó vivir. La cuestión del ejercicio de la violencia política por ejemplo, no sólo fue una alternativa legítima para numerosas mujeres sino también una elección que pudieron conjugar tanto con otras formas de intervención política como con otras actividades vitales como las de ser trabajadoras, estudiantes, madres o hijas. La situamos también en el lugar visible, sin dudas insoslayable, de ser la esposa de Mario Roberto Santucho, el máximo dirigente del PRT-ERP. Pero a la vez, buscamos develar la opacidad de esa condición al atender a los particulares rasgos que ella misma le imprimió. Esto tiene que ver con los modos que puso en juego con sus intervenciones políticas amparados en una gestualidad de mujer enigmática, callada y poco llamativa. Mas también, con la de ser dueña de cierta autoridad en la que combinaba su experiencia intelectual y personal, su trayectoria, sin subrayar con evidencia, quizás alimentando hasta de manera solapada, definiciones y decisiones de su esposo y de la organización guerrillera marxista en la que ambos militaban.

Mostraremos en este trabajo, además, que las tensiones y conflictos que definieron su vida gravitan en las rememoraciones actuales sobre ella, en la construcción de unos recuerdos en los que es posible percibir, como mínimo, una línea de memorias reivindicativas en contradicción con una línea de memorias malditas, como las de guerrilleras rudas y malvadas.

Apostamos, en síntesis, a reconstruir la biografia de una mujer cuya trama vital fue parte de una experiencia compartida con otras mujeres de su tiempo y de sus opciones políticas, sin eludir lo que la vuelve destacable entre esas mujeres y para nuestros propios ojos. 
Orientado por esa pretensión entonces, nuestro trabajo dialoga con un conjunto de estudios que, en clave biográfica, se han esforzado por reponer la vida de las militantes de este período histórico alejándose de tipificaciones heroicas y rehuyendo simultáneamente, presentarlas como personajes célebres e ilustres. Concentrados fundamentalmente en la izquierda peronista y desde un enfoque que se desentiende de la perspectiva de género, estos textos logran explicar ciertos pasajes y dimensiones de las trayectorias de estas mujeres reponiendo sus agencias en función de las decisiones y prácticas políticas que ellas tomaron. ${ }^{2}$

También dialoga con una literatura que se interesó en examinar ese conflictivo pasado a la luz de los múltiples escenarios y formas de participación política femenina durante los años 1960 y 1970. Con una mayor variedad que la contemplada por las biografias, ya que abordan un arco político diverso que comprende desde las organizaciones revolucionarias armadas y no armadas hasta las agrupaciones feministas, ${ }^{3}$ tales investigaciones escudriñan el compromiso de estas mujeres a la luz de dos perspectivas dominantes. La primera es la que sitúa esta dinámica política en un proceso de modernización socio-cultural en donde el "sujeto juvenil" puso en cuestión, acompañando novedosos horizontes culturales, las jerarquías generacionales, de género y de clase, entre otras instancias de poder. La segunda se inclina por ubicar estas prácticas en un proceso de radicalización política que amenazó la reproducción del orden capitalista a partir de distintas iniciativas vinculadas con el surgimiento de organizaciones políticas tanto armadas como no armadas. ${ }^{4}$ Inscriptos en una u otra línea y amparados en la historia de las mujeres y los estudios de género, este universo de trabajos logró reponer a esas jóvenes como sujetos colectivos y heterogéneos, examinando una gran variedad de fuentes y trazando líneas de exploración que renovaron la agenda historiográfica sobre el pasado reciente interrogándose por los discursos y las prácticas de género dentro de las organizaciones políticas y en sus horizontes revolucionarios, el lugar de lo público y lo privado en ese complejo entramado, las relaciones de pareja y familiares en la dinámica política -en particular en lo relativo al ejercicio de la maternidad-, o las pautas de sexuación del castigo. ${ }^{5}$

\footnotetext{
2 Véase en particular, las reconstrucciones sobre Norma Arrostito (Saidón, 2005), Lily Masaferro (Giusani, 2005), Alicia Eguren y Susana Pirí Lugones (Seoane, 2014) y Ana María González (Lorenz, 2018).

3 Véase, por ejemplo, Andújar et al. (2009 y 2010); Grammático (2005 y 2011), Martínez (2009); Noguera (2013; 2019), Oberti (2015), Pasquali (2008); Seminara (2015); Vassallo (2005) y Viano (2011). Dentro de la literatura testimonial se destacan los trabajos de Diana (1996) y la semblanza sobre la teniente Inés en Plis Steremberg (2003).

4 Entre quienes representan la primera tendencia se cuentan los estudios de Isabella Cosse (2010) y Valeria Manzano (2018). Ejemplos de la segunda tendencia pueden advertirse en los trabajos antes referidos de Karin Grammático, Ana Noguera, Luciana Seminara, Cristina Viano, Alejandra Oberti y Violeta Ayles Tortolini, entre otras investigadoras.

5 Para un trabajo pionero sobre el rol de las mujeres en el PRT, véase Pablo Pozzi (2001). Respecto de las relaciones de pareja en las organizaciones revolucionarias, véase por ejemplo Andújar (2009) y Cosse, (2017). En cuanto a la manera en que el género gravitó en la represión estatal y su ferocidad,
} 
Tanto las narrativas biográficas como las que examinan el período a la luz de las dinámicas colectivas del proceso histórico, comparten el uso de la historia oral para hallar las huellas de esos itinerarios politicos femeninos, recurrencia que, en ocasiones, ha sido formulada y puesta en práctica conjugando el género con la memoria y el relato de la experiencia vivida. Existe una extensa literatura que se ha ocupado de esta metodología de investigación, las formas distintivas y beneficios que conlleva su uso para la comprensión histórica, los retos que depara para quien investiga así como las dificultades, recaudos y problemáticas que deben tenerse en cuenta respecto de la edificación de la memoria, principal fuente de la oralidad. ${ }^{6}$ También contamos con una vasta bibliografia que, procedente de la historia y la sociología fundamentalmente, viene reflexionando sobre la manera en que el género atraviesa la construcción de la memoria así como el relato vivencial del pasado. ${ }^{7} \mathrm{La}$ amplitud de su difusión vuelve innecesario realizar aquí un repaso exhaustivo de sus postulaciones centrales. En función de este trabajo, basta con subrayar dos de las utilidades de la historia oral. La primera radica en su potencialidad para recuperar el ambiente social de los procesos históricos, permitiendo hallar nexos entre los acontecimientos vividos por Ana, su propia agencia politica y la trama en que la que intervino. La segunda se vincula con la consecución de una expectativa o una promesa que encierra la oralidad: la del hallazgo de fuentes inesperadas. Como lo han mostrado diversos y diversas historiadoras, el uso de la historia oral no sólo puede ponernos en contacto con una amplia gama de testigos y potenciales testimoniantes. También posibilita detectar papeles y documentación cuya existencia o bien se desconocía o bien se creía perdida (Gatica, 2007; Portelli, 20032004). En esta pesquisa, las entrevistas realizadas con algunas personas nos han provisto, por ejemplo, de cartas personales y fotografias cuyo examen colaboró en descifrar algunos aspectos de la personalidad de Ana, de su vida militante y de su manera de actuar. Asimismo, la historia oral nos ha permitido ahondar en su persona a partir de los recuerdos que, como un caleidoscopio, su familia y sus compañeros tienen sobre ella.

El recorrido por documentación de diverso tipo, tanto oral como escrita, nos conduce a advertir varias cuestiones. La primera refiere a la multiplicidad de papeles, reflexiones, historias y relatos con los que contamos sobre Ana María Villarreal para conocer su trayectoria. La segunda hace al estado fragmentario de tal documentación. La dispersión de las pistas sobre sus huellas en noticias periodísticas, causas judiciales o retazos de recuerdos de quienes la conocieron, podría desalentar los intentos por componer una trama ordenada de su vida al

veáse D’Antonio (2009, 2013 y 2016). Un balance general sobre el grueso de estos tópicos se encuentra en D’Antonio y Viano (2018).

6 Véase, entre otros, Portelli (2016), Schwarzstein (2001), Thompson (2003-2004),

7 Véase, entre otros estudios, Andújar (2014); Gatica (1997); James (2004); Jelin (2002), Viano (2008). 
obstaculizar la posibilidad de internarse por situaciones complejas, por pasajes de esa experiencia que a primera vista resultan de dificil sondeo. Sin embargo, y como tercera cuestión, debemos destacar que como casi siempre en el oficio de contar el pasado, el problema no se encuentra en realidad ni en la cantidad de fuentes ni en su estado. $\mathrm{O}$ al menos no sólo allí. Más bien, se sitúa en las preguntas que formulamos para acercarnos a ese pasado y en las inquietudes que nos motivan a conocerlo. Que no se haya puesto en valor debidamente la vida de Ana hasta ahora no ha tenido que ver, entonces, con la documentación existente sobre ella, abundante por otro lado para algunas partes de su trayectoria. Fue nuestro interés por comprenderla lo que nos permitió reponer e interrogar un acervo documental rico y variado, compuesto por testimonios orales (obtenidos en entrevistas realizadas a familiares directos de Ana, compañeros y compañeras de militancia, abogados vinculados a la defensa de presos politicos), cartas personales, fotografias, expedientes judiciales, documentos políticos, prensa comercial y política (específicamente perteneciente al PRT-ERP).

Con estas fuentes en mano, este trabajo se compone de tres secciones. La primera examina aspectos de la vida de Ana María Villarreal que brindan pistas sobre las bases de sus decisiones politicas. La segunda se centra en las memorias que han construido sobre ella familiares y compañeros. La tercera se detiene en la muerte, el entierro y ciertas disputas presentes en las memorias sobre su figura. Lo cierran unas conclusiones que reflexionan sobre el género como registro histórico y sobre las opciones brindadas por esta perspectiva para jerarquizar los fragmentos de una vida singular en las tramas más amplias relacionales -y generizadas- de la participación temprana de las mujeres en la vida política de nuestro país.

\section{Artista plástica, alfabetizadora y guerrillera: una mujer de época}

Ana María Villarreal nació en Salta el 9 de octubre de 1935 en el seno de una familia que no pasaba penurias, aunque tampoco pertenecía a los sectores acomodados de la sociedad local. Fue hija de Edmundo Diego Villarreal, un restaurador de piezas artísticas, y de Eloísa Guillermina Cassasola. Tuvo dos hermanos, Sergio Edmundo y Carlos Edelmiro -quienes se dedicarian en la adultez a la decoración y el comercio respectivamente-, y una hermana, Cristina Eloísa -que se convertiria en profesora de Biología-.

Cursó sus estudios primarios en "Domingo Faustino Sarmiento", un colegio donde se impartían clases de música, dibujo, corte y confección, educación doméstica y religión. El secundario lo hizo en "Santa Rosa de Viterbo", una escuela para niñas, reconocida por el Ministerio de Educación como Escuela Normal de Maestras. Fue buena alumna, aunque no sobresaliente; la atraía historia, pero no matemáticas, materia con la que tuvo problemas en su secundaria (Diana, 1996: 313). Posiblemente fue la causante de un traspié en sus estudios, cuando tuvo 
dificultades para rendir una materia de años anteriores y obtener su

título de maestra. Simultáneamente, asistió a la escuela provincial de Bellas Artes "Tomás Cabrera", espacio fundado por artistas salteños en el que aprendió pintura y escultura bajo la influencia de Alfredo Bernier, pintor con el que además tomó clases particulares. También aprendió danzas folklóricas junto a su hermana (Genaro, S/F). Leía, escuchaba música y dibujaba mucho.

Durante la segunda mitad de los años `50, se recibió y estudió Artes Plásticas en la Universidad Nacional de Tucumán (UNT). No era tan inusual en esos tiempos que una joven -sobre todo de clase media- pudiera concluir sus estudios secundarios y asistiera luego a la universidad. Ese camino que Ana siguió y cultivó esforzadamente fue compartido con otras mujeres de su generación que optaron por inscribirse también en la UNT o dirigirse a Córdoba, La Plata, Rosario o Capital Federal para ingresar a la Universidad de Buenos Aires. Lejos de ser descabellado, que las mujeres jóvenes siguieran una carrera universitaria se había vuelto un horizonte deseable y legítimo. ${ }^{8}$ En ese contexto fue que conoció a Mario Roberto Santucho, Roby para sus amigos y familiares. Tal vez en la casa de una amiga o quizás en una fiesta. Para 1959 ya estaban juntos. El 15 de junio de 1960, un año después, cuando ella ya tenía 25 años y él 24, se casaron.

Amílcar Santucho, uno de los hermanos de Roby, recordó que fue el único familiar que participó de la boda y quien lo alentó a realizar un festejo, ya que la sencillez y la opción rigurosa de vivir apenas con lo necesario era la posición que había asumido la pareja. Recordando sus primeros intercambios al momento de conocerse con Ana y refiriendo a su singularidad, evocó una de las primeras preguntas que ella le formuló:

“¿Le gustan las películas rusas?" Yo me sorprendi, porque estaba hablando de otra cosa, pero al mismo tiempo su pregunta, que fue hecha muy espontáneamente, me resulto muy simpática. Le contesté que sí y ella, con una sonrisa, replicó: "A mi también, me encantan". No sé por qué, pero con eso me compró. (...) Era muy especial.” (Diana, 1996: 329)

\footnotetext{
8 Según datos censales, a fines de los años '50 y comienzos de la década siguiente, más de dos tercios de las jóvenes de 20 a 24 años habían alcanzado la enseñanza secundaria y casi la mitad, el nivel superior (Cosse, 2014). De tal modo, las universidades, sobre todo aquellas en las que se abrian nuevas carreras como Psicología, Sociología o Antropología -e incluso en carreras tradicionalmente masculinas como Derecho y Medicina- vieron aumentar la matricula femenina, que pasó de conformar el $5 \%$ en la década de 1930 , al $38 \%$ a fines de los años ${ }^{`} 60$ y a un $40 \%$ al promediar los años ${ }^{\circ} 70$ (Barrancos, 2007: 220).
} 
En su descripción, Amílcar la retrata como delicada y frágil; silenciosa y suave, pero fuerte y tenaz; capaz de despertar con su dulzura y firmeza la pasión de su hermano:

"(...) Se descalzaba y parecía que se deslizaba, habia una levedad en sus movimientos, como si no tocara el suelo... Al mismo tiempo, a pesar de esa fragilidad tenía agallas y fuertes convicciones propias, no se le podian imponer cosas. Creo incluso que muchas de las decisiones que Roby tomó estuvieron influidas por ella, que fue revelando una gran capacidad política (...)" (Diana, 1996: 329).

Ana y Roby decidieron emprender un viaje de luna de miel con destino a Estados Unidos, recorriendo varios tramos de América Latina por la Costa del Pacífico. Las cartas escritas por ella a sus padres y a su hermana atestiguarian su honda sensibilidad ante un arte indígena que advertía en detalle, y junto a ello, el impacto que le producian las comunidades con las que se iban encontrando. Retrató a Potosí el 14 de enero de 1961 como "lo más extraordinario que vi en arte colonial (...) todo potosino parece estar amándolo por todas las cosas a ese cerro (....) que parece fuerte (a la distancia)". 9 En Panamá, ciudad en la que estaban a comienzos de marzo de ese año y a la que Sayo describirá como "típicamente yanky, (sin) movida nacional",10 decidieron comprar un Dodge modelo 1950 para seguir el recorrido con más rapidez y comodidad, esperando llegar el 7 de marzo a Méjico, donde se quedarian hasta el día 15 para luego emprender rumbo a Guatemala. ${ }^{11}$ Un mes más tarde, Ana le escribía a su madre desde Washington comentándole sus impresiones sobre la capital norteamericana y sobre Nueva York, ciudad en la que habían estado tan solo unos dias antes. En uno y otro lugar, ella y Roby habian "asistido a clases de las famosas universidades", no sólo interesados en conocer "el ambiente universitario" sino también porque al dictarse en español, esas clases les permitían entrar en contacto con "Historia del Arte Americano, Política económica de América Latina, Literatura americana, etc.",12 materias cuyos contenidos los acercaban a algunas de las miradas que circulaban sobre América Latina en la academia estadounidense. A su regreso pasaron por Cuba, entusiasmados con una revolución que estrenaba ese otro mundo posible.

Ya en Argentina, en 1961 nació Ana, la primera de tres hijas. Luego vinieron Marcela y Gabriela. La maternidad no le impidió a Ana María terminar sus estudios, cosa que logró en 1962 con la obtención de su título de Licenciada en Artes Plásticas de la UNT.

\footnotetext{
9 Carta de Ana a sus padres desde Bolivia, 14 de enero de 1961. Archivo de las autoras.

10 Carta de Ana María Villarreal a sus padres desde Panamá, 1 de marzo de 1961. Archivo de las autoras.

11 Ibídem.

12 Carta de Ana Maria Villarreal a sus padres desde Washington, 11 de abril de 1961. Archivo de las autoras.
}

\section{anuario.}


Mientras cursaba su carrera universitaria, se incorporó al Frente Revolucionario Indoamericanista Popular (FRIP), organización creada hacia 1961 por Mario, Francisco y Oscar Asdrúbal Santucho en Santiago del Estero (Pozzi, 2001). Ana no sólo militó en el sector universitario de este grupo. ${ }^{13}$ También ilustró el último número de la revista Dimensión, una publicación vinculada en uno de sus ciclos con el FRIP, que salió de manera esporádica entre los años 1956 y 1962.14 En ese entonces comenzó a dictar clases como auxiliar docente en la cátedra de Pintura, cargo al que renunció sin embargo al poco tiempo.

Imagen 1: Dibujos de autoría de Ana María Villarreal de Santucho

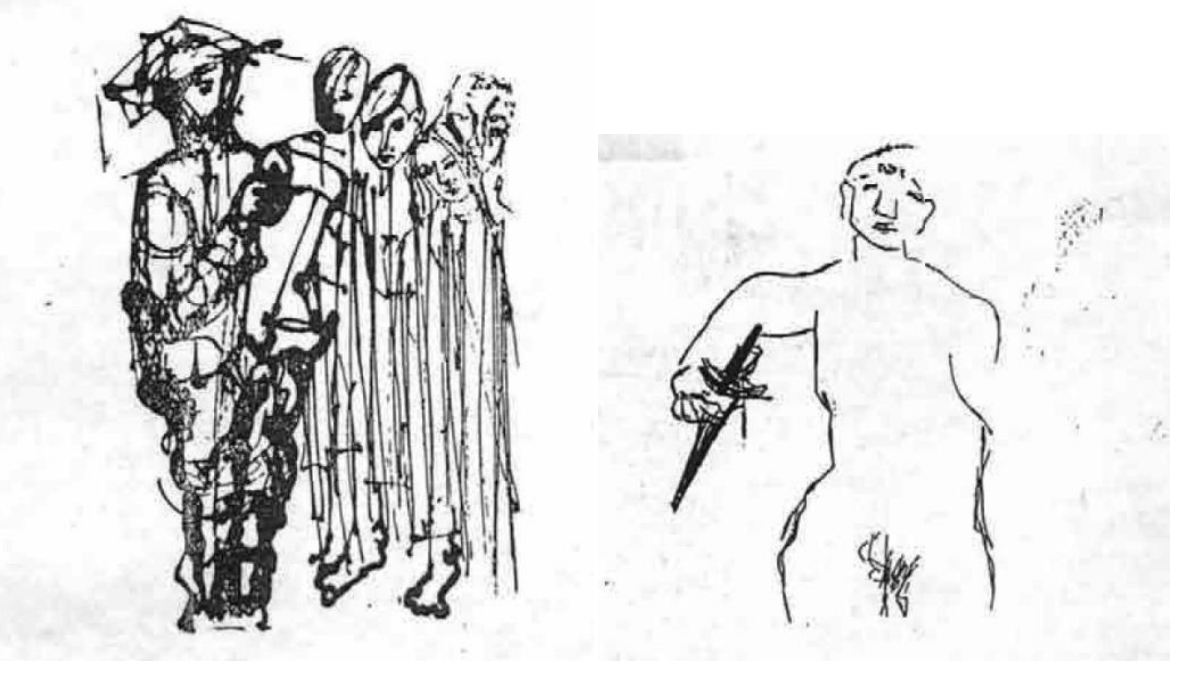

Fuente: Dimensión, Año III, N 6 (AAVV, 2012). ${ }^{15}$

En 1965, cuando el FRIP y Palabra Obrera -organización trotskista dirigida por Nahuel Moreno con incidencia en Tucumán, Córdoba, Rosario, Buenos Aires y Bahía Blanca- confluyeron para crear el PRT, Ana estuvo alli. De acuerdo con

13 Según Pozzi (2001), el FRIP tuvo tres vertientes: la universitaria, conformada en la UNT y cuyo núcleo activista central estaba en Ciencias Económicas; la agrupada en torno a la librería Dimensión, que editaba el periódico del mismo nombre, y la tercera vinculada con cierto nacionalismo de izquierdas.

14 La colección completa de la revista fue publicada en el año 2012 por la Biblioteca Nacional bajo responsabilidad de Horacio González. Está disponible en Internet. Véase AAVV, 2012.

15 Agradecemos a Gabriel Rot por habernos advertido y brindado información sobre la existencia de estos dibujos. 
Estela Assef, una de sus compañeras de militancia, entre octubre de 1967 y mayo de 1968 ambas integraron un grupo dedicado a enseñar a leer y a escribir a trabajadores y trabajadoras del Ingenio San José, en la provincia de Tucumán. Igual empeño se llevó a cabo en la sede de la Federación Obrera de la Industria Azucarera (FOTIA), sindicato de filiación peronista.

Estela recordó también que Ana padecía de cierta dolencia pulmonar que, si bien no era tuberculosis, exigió al menos una internación. En esas circunstancias:

“(..) yo fui a cuidar a las chicas, nos turnábamos con otras compañeras. Vivian en una calle que se llamaba Isabel La Católica y (...) siempre cuidaba el detalle que ella más marcaba, que era éste: las chiquitas tenian que comer asi su pote, así ella no comiera durante el dia, las chiquitas tenian que comer yogur, todos los dias... vasitos porque antes de litro no vení.... Las chiquitas tenian que comer vegetales, tenían que comer fruta, y bueno esas cosas que nosotros le respetábamos, iporque no éramos madre ninguna! Ella era la única que era madre en ese momento...". 16

El trabajo social que Sayo hizo también supuso interactuar con las compañeras, incluso promoviendo, acompañando y adelantando las posibilidades de optar por una maternidad elegida. Nuestra entrevistada recordó cómo preguntaba en el ingenio "¿y usted cómo se cuida?".

En ocasión de reunirse el V Congreso del PRT-El Combatiente en 1970,17 donde se decidió la creación del Ejército Revolucionario del Pueblo (ERP) no como una extensión del partido sino como brazo armado del pueblo (Pozzi, 2001), Ana estuvo presente, aunque sin derecho a voto porque no era delegada de ninguna regional. Ese rol sólo lo tuvieron otras dos mujeres allí, Nélida Augier y Clarisa Lea Place, que votaron como delegadas de la regional Tucumán (Diana, 1996: 92). En ese momento Clarisa mantenía una relación íntima con Roby; se había convertido en su otro amor. Era 12 años más joven que Ana y estudiante de Derecho en la UNT. El vínculo amoroso había comenzado entre fines de 1968 y principios de 1969,18 en una etapa en la que Roby se encontraba separado de Sayo. A pesar de ello, la relación de Roby y Clarisa recibió fuertes cuestionamientos. Tal vez, para algunos sectores del Partido la monogamia y la fidelidad eran valores importantes que debian preservarse.

En ese entonces, Ana se habria quedado con sus hijas en casa de sus suegros en Santiago del Estero (Tarcus, 2007). Sin embargo, lo sucedido luego con el matrimonio se vuelve confuso. Si bien las fechas y las circunstancias no son del

\footnotetext{
16 Entrevista de las autoras con Estela Assef (Tucumán, 30 de julio de 2018).

17 Esta organización fue resultado de la ruptura del PRT en 1968 en función de la valoración de la conveniencia de la lucha armada como herramienta para la revolución: el PRT-La Verdad, liderado por Nahuel Moreno, y el PRT-El Combatiente, liderado por Mario Roberto Santucho.

18 Entrevista de las autoras con Luis Lea Place (Buenos Aires, 28 de julio 2018).
} 


\section{ANDREA ANDÚJAR - DÉBORA D`ANTONIO - MÓNICA GATICA}

todo claras, en algún momento del segundo semestre de 1970 ella, nuevamente con Roby, se habría instalado en Córdoba retomando una convivencia armónica que incluyó también la presencia de las tres hijas. ${ }^{19}$ Lo cierto es que, sorteando encuentros y desencuentros amorosos, en 1970 Ana facilitó la fuga de Roby de la prisión de Tucumán; y en junio de 1971, fue Roby quien colaboró con la fuga de Ana de la cárcel del Buen Pastor, en plena ciudad de Córdoba.

Desde marzo de 1971 Sayo estaba recluida alli, ya que había sido atrapada y herida el día 11 en un reparto de alimentos en el humilde barrio Marcelo T. de Alvear, de la capital cordobesa. Desde el momento en que llegó comenzó a pensar en cómo fugarse. En la tardecita del 11 de junio, un comando del PRT-ERP que luego se presentaría como "Comando Lezcano, Polti y Taborda", conformado por dos militantes armados y vestidos con uniformes policiales entró en la cárcel cuando, al anochecer, una empleada y una ayudante arrastraban la basura del edificio hacia la acera. Se apostaron cercanos a la puerta del contra frente donde no había guardia policial y, tras inmovilizar a estas mujeres, abrieron una puerta cancel detrás de la cual ya estaban cinco presas políticas prestas a salir. El escape puertas adentro lo había planeado y dirigido Ana Maria Villarreal de Santucho, que se escapó con otras cuatro militantes: Diana Triay de Llorens, Alicia Quinteros, Silvia Urdampilleta, que pertenecían al PRT-ERP, y Cristina Liprandi de Vélez, de Montoneros. Se sospechó que existían cómplices dentro de la cárcel. Este evento, significativamente, nos adelanta que la fuga de Rawson no fue la primera acción de este tipo coordinada por las organizaciones y nos permite destacar, a su vez, la urdimbre y el sustento en el vínculo de estas compañeras. Los hechos sucedidos en la cárcel de Córdoba pusieron en evidencia las relaciones que a tal fin habian entretejido las mujeres del PRT-ERP y las de Montoneros. También, aunque tal vez mucho menos visible, que esta articulación fue ideada centralmente por Ana y sus compañeras, hecho que habría transformado asimismo la política represiva del Estado. Cuando las mujeres se escaparon, pusieron en evidencia la vulnerabilidad del sistema carcelario. Tal motivo apuntaló la decisión de secularizar el castigo y el encierro femenino hasta ese momento en manos justamente de una institución religiosa administrada también por mujeres (D`Antonio, 2013 y 2016). ${ }^{20}$

Ana tuvo diversas moradas, todas en clandestinidad por su condición de prófuga. Córdoba, Buenos Aires, Tucumán y Salta fueron algunos de los lugares donde se cobijó. Cuando a comienzos de febrero de 1972 estaba por tomarse un colectivo desde la salteña ciudad de Metán, la encontraron y la acusaron de portar

\footnotetext{
19 Este señalamiento surge de las reflexiones provistas por Dora Genaro (S/F) y de una comunicación personal de Julio Santucho brindada a través de un diálogo con Luis Lea Place el 29 de septiembre de 2018. Archivo de las autoras. Para una versión sobre la ruptura entre Clarisa y Roby, y del retorno de este último con Sayo, véase Augier (2012).

20 Agradecemos a Ana Noguera su disposición generosa de compartir con nosotras diversas fuentes sobre este acontecimiento.
} 
documentos falsos y un arma robada. La detuvieron, y luego de maltratarla y torturarla, manteniéndola de pie toda la noche, la trasladaron al buque Granaderos, una cárcel flotante que para ese entonces alojaba a presas y presos políticos. Su defensa argumentó la violación del debido proceso y la anticonstitucionalidad de la Cámara Federal en lo Penal, conocida como Camarón, institución creada para intervenir en casos caracterizados por el Poder Ejecutivo Nacional como "delitos de subversión". La defendieron varios abogados: Amílcar y Manuela Santucho, Carlos Zamorano -experimentado letrado vinculado al Partido Comunista-, y Carlos Sánchez Viamonte, un reconocido penalista sin vínculos con la izquierda pero convencido de los atropellos del régimen militar. Roby, por su parte, la instaba a solicitar su traslado al penal de Rawson. Sayo se avino a ese pedido, tal vez porque ya tenían en mente la organización de la gran fuga, y el 9 de julio, apenas fue dictada su sentencia, llegó esposada a la prisión patagónica. Amílcar Santucho sostuvo que:

"Me urgía constantemente que apurara la resolución del caso, cualquiera fuese el resultado, porque quería estar en Rawson para el momento de la fuga que sabia que planeaba Roby. El traslado se concretó, pero desgraciadamente, ese fue su final". (Diana, 1996:330)

Compañeras y compañeros de cárcel, así como de la organización partidaria, han sostenido que por su trayectoria Ana ofició como responsable de las presas de su propia organización del penal, lo que se corresponde con el lugar que ella ocupó en la histórica fuga de 1972, como luego veremos. Sayo fue una de las mujeres que, junto a otros compañeros y compañeras, se fugaron y luego debieron entregarse para ser trasladados a la base Almirante Zar. Como se sabe, en la madrugada del 22 de agosto fue fusilada junto con otrxs quince guerrilleros detenidos. Ana tenía treinta y seis años. Según consta en la Causa $\mathrm{N}^{\circ} 12-\mathrm{F}^{\circ} 122$, conocida como Causa "Masacre de Trelew", ella estaba embarazada de por lo menos cinco meses. ${ }^{21}$

Sus restos fueron velados en la sede del Partido Justicialista, en la ciudad de Buenos Aires, junto con los de María Angélica Sabelli y Eduardo Capello. Después de que la policía montada al mando el comisario de la Policía Federal Alberto Villar embistiera contra la sede partidaria donde se estaba desarrollando el funeral colectivo, el ataúd de Sayo fue llevado a un cementerio en el Gran Buenos Aires. "Sayito fue depositada en el monumento de Nélida Navajas, suegra de mi hermano Julio César, en Boulogne”, sostuvo Blanca Rina Santucho (2004:87), hermana de Roby. Luego, su padre logró recuperar el control de los restos de su hija y llevarlos a Salta.

\section{Donde la memoria ardia}

21 Esta causa se encuentra disponible en linea. Véase https://www.cij.gov.ar/nota-10022Condenaron-a-prisi-n-perpetua-a-tres-imputados-por-la-Masacre-de-Trelew.html. 
La labor de escribir la historia de Ana María Villareal de Santucho además de contribuir a expandir los modos de comprensión del pasado reciente, nos incentiva a reflexionar acerca de cómo ella fue y es recordada entre sus familiares y compañeros de militancia. En varias de las entrevistas realizadas recibimos inicialmente, y más que nada de parte de los varones de su propia organización, una subestimación respecto de lo que podrían aportar sobre ella. En buena medida, esto se debe a que las memorias sobre su presencia y agencia política han quedado eclipsadas por la figura de Roby y por la cesura que supuso su asesinato. Sin embargo, cuando logramos enunciar las preguntas adecuadas emergen recuerdos sobre su persona, su carácter e incluso sobre su participación en hechos destacados de la historia de su organización.

Pedro Cazes Camarero, un antiguo militante que conoció a Sayo en los años de creación del FRIP, la recordó como una mujer "de pómulos salientes, cutis oscuro y enormes ojos negros, de aspecto indígena y huesitos delicados, era pequeñita de tipo quichua o aymara".22 Pedro sostuvo que en las reuniones que compartió con ella "casi no hablaba nada". Aunando el perfil de ella con su compañero afirmó en otros pasajes de la entrevista, que en verdad tampoco "el Negro (Roby) hablaba mucho". Cazes Camarero no identificó esto como una falta de carácter sino como un estilo de liderazgo propio de los cuadros políticos que se habian formado al calor de las luchas de los obreros rurales del noroeste del país, acostumbrados más a escuchar que a hablar. Resulta interesante reparar en una anécdota que contó Pedro sobre algo sucedido al finalizar un plenario, en el marco de una charla informal entre mates y tortas fritas. En esa ocasión, Sayo, más cómoda, se explayó contando numerosos detalles de su viaje por los Estados Unidos, así como distintos episodios sobre sus días en la Cuba de la naciente revolución. Allí, en espacios menos disciplinados y jerarquizados, a esta militante de tonos apocados le resultaba más sencillo tomar la palabra. Cazes Camarero la rememoró también a propósito de un viaje realizado unos años después desde Tucumán a Buenos Aires, cuando participó en las reuniones preparatorias para el III Congreso del PRT en 1967 con el fin de evaluar qué pensaban los cuadros medios de la organización sobre la posibilidad de avanzar hacia la estrategia de lucha armada. A su juicio, el nivel cultural y humanístico de Ana junto con el uso de numerosas "categorias del libro de Arnold Hauser sobre historia social del arte" conformaban sobradas muestras de cómo ella percibía y reflexionaba acerca de la realidad local. ${ }^{23}$

En otro pasaje de la entrevista, Pedro explicó que en la generación siguiente a la suya "hubo una especie de endiosamiento con los Santucho", aun cuando, para nosotros mismos, "eran tan solo cuadros políticos importantes con quienes

\footnotetext{
22 Entrevista de las autoras con Pedro Cazes Camarero. (Buenos Aires, 12 de julio de 2018).
}

23 Ibidem. 
compartíamos la vida diaria". Así relativizó la importancia del affaire que tuvo "el Negro" con Clarisa Lea Place, simplemente porque esa relación no lo llevó a culminar en una ruptura con su esposa. Tampoco fue demasiado relevante para él lo que se ha ventilado en la causa por la masacre de Trelew acerca del embarazo de Sayo, pues sostuvo que eso "no puede pensarse más que como parte de la relación entre esos dos jefes políticos ya maduros". Los recuerdos de este militante fundador del PRT-ERP y director de "El Combatiente", son claros a la hora de describir la singularidad norteña de esta mujer y su rol en los albores de la corriente política que los cobijó en los años siguientes. También, respecto de la sensibilidad y de la valoración de Sayo como un cuadro político en la organización. Su remembranza y su relato se manifiestan menos interesados, sin embargo, en lo que se podría definir como cuestiones personales de esta mujer y aunque se pone a distancia de las visiones endiosadas sobre los líderes revolucionarios, a la hora de reconstruir sus figuras desestima incluso exiguas fisuras en sus trayectorias vitales.

Carlos González Gartland, uno de los abogados defensores de presos políticos durante los años setenta, hacedor de la emblemática Asociación Gremial de Abogados de la Capital Federal (Chama, 2000), comenzó su entrevista analizando el rol de las mujeres en las organizaciones revolucionarias y el lugar que tenían los abogados en sus defensas jurídicas. Explicó que "los jueces sabían que las compañeras eran peores que los compañeros porque tiraban con las dos manos y porque... eran capaces de meterle un tiro en medio de las cejas a alguien si era necesario." 24 Esta afirmación pondera lo desafiante que podian resultar las mujeres para el poder judicial en la lucha politica de esos años. González Gartland ofrece detalles sobre la figura de Ana en el PRT-ERP en tanto explica que, para articular las defensas en juicio, los abogados debian empaparse de ciertos pormenores de la vida de las y los militantes. En este sentido, sostuvo que Sayo "no tenía solamente una relación de coito con el "jefe" sino que gozaba de una jerarquía dentro de la organización” y agregó sin dudar "pues participaba del aparato militar". Ahondando en las estrategias con las que preparaban los escritos judiciales para auxiliar a las personas detenidas, el abogado explicó que cuando era posible intentaban alivianar las responsabilidades de un jefe o jefa política o militar con argumentos particularmente despolitizados. De modo que muchas veces se alegaba ante los jueces, y en particular respecto de las mujeres, que ellas no habían tenido responsabilidad alguna en tales o cuales hechos justamente porque solo eran las esposas "de". Enfatiza, el histórico abogado que: "y claro eso era todo pura mentira". También sostuvo que Ana Maria había formado parte del primer grupo de fugados del penal de Rawson entendiendo que esto era así porque "esas personas eran consideradas por las organizaciones como las más valiosas, hombres o mujeres que tenian habilidades especiales o que eran jefes de inteligencia o jefes militares". 25

\footnotetext{
24 Entrevista de las autoras con Carlos González Gartland (Buenos Aires, 27 de junio de 2018). 25 Ibídem.
} 
El testimonio de Alicia Sanguinetti, otra militante de la organización guerrillera marxista, reviste múltiples aristas que vuelven muy sustantivo su aporte no sólo porque compartió la cárcel con Ana en el penal de Rawson sino también porque pudo aludir a la importancia de ella en los frentes de masas en los que se encuadró y en particular, a su experiencia de trabajo en los ingenios, como retratara Assef. Ella comentaba que "la reconozco como muy humilde y como muy tímida. ¡O sea más que tímida con todas esas características de las mujeres del norte, de aquellas épocas, no! O sea: sumisa, pero por otro lado con mucha fuerza, con mucha fuerza." 26 En ciertos pasajes de su relato puede vislumbrarse un reconocimiento e incluso una verdadera admiración por la trayectoria de Ana. También pareciera que el tiempo compartido en la cárcel tiene una densidad que distingue con particularidad ese vínculo. En medio de la narración referida a los preparativos para la fuga, recordó que:

“(...) No llega ni un poquitito antes de dos meses de la fuga...Ella toma parte a pesar de que ya existían equipos que preparaban la fuga, o sea... Yo la tengo mucho más recordada a Sayo cuando nos daba clase de El Capital y de economía. Éramos un equipo de cinco porque nos mandaban, nos decian al que le tocaba historia, al que le tocaba esto, lo otro, etc. Y yo sé que, en un momento dado, cuando se armó el equipo, un compañero, o una compañera era, que no conocía la historia de Clarisa y de Sayo la quiso poner a Clarisa en el equipo: el de estudio de economía. Y Sayo muy timidamente y elegantemente dijo que no, que cinco compañeras eran suficientes, y que la preparación del tema de economía de Clarisa era mayor de la que teníamos nosotras, o sea, hizo todo lo posible y consiguió de que Clarisa no estuviera en el equipo. Está bien ya que la relación con el Roby, con Clarisa se habia roto, pero bueno... era estar conviviendo... las dos parejas de Roby" (Entrevista de las autoras con Alicia Sanguinetti, Buenos Aires, 27 de julio de 2018).

La respuesta que dio Sayo sobre integrar o no a Clarisa puede ser interpretada en distintas claves e incluso, suponer cierto carácter desafiante o irónico. “iSayo era así, nosotros le deciamos nuestra querida vietnamita! O sea, ese fue el nombre que se le puso a Sayo adentro del penal. ¡Porque aparte tenía esos ojitos que tenía, y esa piel donde no había una sola arruga! ¡Además de eso no había un solo gramo de grasa!". ${ }^{27}$ La forma de denominación cariñosa que le asigna Alicia en la entrevista muestra la valoración por parte del colectivo con el que compartió la reclusión en Rawson. Pero también emerge de allí que Sayo era una mujer muy diferente a ella, con características que, además, la singularizaban en algún punto.

De conjunto, con distintas perspectivas, estas miradas colocan a Ana en los orígenes de la tradición de la corriente que daría lugar posteriormente al PRT y al

\footnotetext{
26 Entrevista de las autoras con Alicia Sanguinetti (Buenos Aires, 27 de julio de 2018).
}

27 Ibídem. 
ERP portando el valor de haber gravitado en la política durante esos momentos fundacionales. También le otorgan un reconocimiento destacado a su militancia en los ingenios y en su papel de alfabetizadora de las familias rurales tucumanas. Mientras hay quienes subrayan su rol tímido y acallado, otros reponen sus modos desafiantes. Es reconstruida asimismo como una mujer refinada e interesada en la teoria politica. Hay quienes resaltan sus preocupaciones como madre y quienes remarcan sus desavenencias con quien fuera la amante de su compañero. En los obituarios de la organización, escritos al año de su asesinato en agosto de 1972, se señala que "Es muy dificil para la compañera de un gran revolucionario ser alguien por sus propios méritos en el dificil camino de la revolución. Generalmente ellas quedan ocultas por la luz de sus esposos, reducidas a ser "la compañera de "fulano".28 Sin embargo, Ana María Villarreal parecía haberlo conseguido pues, según continuó describiendo el periódico guerrillero, había logrado ser no solo "una esposa y madre ejemplar, sino también, y ante todo, una mujer de su pueblo, una combatiente revolucionaria de primera línea". ${ }^{29}$

La familia, como no podía ser de otro modo, recuerda a Ana María dándole relevancia a otras aristas y dimensiones de su vida, a los aspectos más íntimos. Por ejemplo, Blanca Rina Santucho repasa a través de hechos claves distintos fragmentos de la historia de esta familia colocando a Sayo en ese escenario. Ella aparece en la querida casa de dos plantas de la calle Absalón Rojas 926 en Santiago del Estero, donde, como parte de los deseos de Francisco -suegro de Ana-, fue cobijada junto con Roby luego de casarse el 15 de junio de 1960. Recuerda también a la pareja en medio de encuentros familiares donde dominaban los bailes y las guitarreadas. Todos momentos festivos que van tener su contrapunto dramático a comienzos de los años setenta cuando varios de los hermanos Santucho y la misma Sayo ingresen a la vida político-militar. El relato de Blanca Rina se desordena al calor de la travesía por la que pasa su familia en la huida de la persecución de las fuerzas de seguridad y porque, en ese desapacible contexto, muchos de sus seres queridos pierden la vida. Los hechos se jalonan con el asesinato de Sayo y luego con la muerte de su hermano Roby el 19 de julio de 1976. Los recuerdos que repone se cierran con la diáspora del exilio de sus familiares en distintos lugares del mundo. Blanca Rina, por un lado, muestra a su hermano como "un revolucionario de excepción, porque a su solidez ideológica, a la perspicacia política, a la audacia, la decisión y el coraje para emprender la conquista por el poder, él tenía un profundo amor a su pueblo" (Santucho, B, 2004:65). Por otro, presenta a Sayo de forma más descriptiva y con menos adjetivaciones, con frases como: "fue detenida y herida", "fue llevada a la cárcel del Buen Pastor atendida por religiosas", "en audaz operativo la liberaron", "fue detenida nuevamente en un viaje a Salta", "fue juzgada por la cámara del terror", "a pesar de la brillante defensa fue condenada por cargos como asociación ilícita y tenencia de armas".

28 Estrella Roja No 23, 15 de agosto de 1973. Extractado de De Santis (2006).

29 Ibídem. 
Por su parte, Marcela Santucho, una de las hijas de Sayo y de Roby, prioriza la historia de su padre, reponiendo en su relato a su abuela Manuela y a su abuelo Francisco, quien se involucró políticamente en Santiago del Estero, construyó un lugar distintivo en ese espacio y legó a sus hijos un pasar económico holgado que les facilitó formarse profesionalmente como abogados o contadores. Al repasar las intervenciones politicas de su familia, Marcela destaca la sensibilidad de los Santucho ante la injusticia social y las preocupaciones indigenistas en su provincia. Las notas en el periódico "El Chasqui", la revista bilingüe "Aquí América", la publicación "Integración" y la librería "Dimensión" son entendidas como instancias que, en la segunda mitad de los '50, se articulan como parte del suelo fértil para gestar la lucha revolucionaria y la vida armada. La relación del futuro dirigente del PRT-ERP con la provincia de Tucumán, y en ella con las universidades y los ingenios azucareros, ocupan un lugar notorio en la mirada de su hija. Es en ese contexto donde Marcela encuadra la relación entre sus padres refiriendo a ese encuentro como "amor a primera vista", un amor que se trasluce en las cartas de amor que ellos intercambiaron entre sí y con sus familiares en el viaje por Latinoamérica que referimos anteriormente. Y es al abordar la captura de su madre por las fuerzas de seguridad cuando intenta igualar los compromisos políticos de Ana y de Roby. Así subraya que, desde la cárcel del Buen Pastor, Ana siguió gestionando la vida de sus hijas y recuerda la firmeza de su carácter al solicitarles a sus suegros que no debian tener miedo por lo que estaba sucediendo (Santucho, M, 2008: 136). También repone el cimbronazo que provocó en su vida la muerte de su madre "dando lugar a una vida de tristeza, incomprensión y cada vez más inestabilidad, me volví más introvertida en la escuela, más callada, más pensativa en las clases (...)" (Santucho, M, 2008: 227). Marcela no culpa a Ana de sus decisiones políticas ni de las consecuencias que conllevaron las mismas. Por el contrario, responsabiliza de su sufrimiento, por ejemplo, a su maestra de sexto grado que conociendo su orfandad fue únicamente cruel y estricta a punto de hacerle repetir el grado infringiéndole asî "una derrota personal porque mi familia siempre me había Inculcado que mi único deber era estudiar, ser buena alumna y reprobar el grado era una deshonra" (Santucho, M, 2008: 228).

De la memoria de Amílcar Santucho vale la pena retomar cuando da cuenta de las falaces y superficiales caracterizaciones que se han realizado sobre ella y señala: "E1 temple de Sayo para las acciones armadas originó una especie de leyenda a su alrededor e incluso se dijo que ella había matado al guardia, cosa imposible porque estaba en el segundo grupo y la muerte se produjo cuando salió el primer grupo. (...) Ana permanece en mi recuerdo y creo que en el de todos aquellos que la conocieron como un ser humano excepcional" (Diana, 1996: 331)

Por último, Cristina, hermana de Sayo, la recuerda callada, observadora, reflexiva; de pocas palabras, pero sarcástica y un tanto burlona. Tempranamente, en su

\section{anuario.}


adolescencia, contradijo y desafió la autoridad del padre, situada en un conflicto familiar que tal vez haya estado en el sustrato de la partida del hogar de origen. Cristina recuerda que Ana se formó con importantes maestros plásticos y musicales, y la trae a su memoria encerrada, leyendo, escuchando música, una joven "de avanzada" con criterio político e indiferente a comentarios malintencionados. Aunque descriptiva, es muy importante su interpretación sobre la afirmación materna en relación a que "Sayito era una chica gustadora". Su amor con Roby demandó admiración y eso fue lo que logró. Mas también supuso una actitud prudente y parsimoniosa, crítica y firme, con la que lo amó hasta el final. En palabras de Cristina, "Nunca vi una pareja que se amara como ellos se amaron, lo demostraban en la mirada, en las sonrisas, en el trato, era algo especial ... yo notaba como que siempre existía una atmósfera de amor alrededor de ellos. Sé que realmente se amaron mucho" (Diana, 1996: 313-314).

Como puede advertirse, las y los familiares de Sayo la recuerdan sensible y crítica, comprometida con el universo político, pero también con el familiar. Entre sus seres queridos no aparecen grandes controversias en torno a su figura. Sus hijas no cuestionan sus decisiones como sí lo hicieron otros hijos de la generación de las y los militantes setentistas respecto de las resoluciones de sus padres y madres. También quedan suspendidas las tensiones que pudieron suscitarse con la ruptura matrimonial de fines de los años ' 60 y por la relación amorosa con la joven Clarisa Lea Place, o ante las desarticulaciones provocadas en el orden familiar con la decisión de tomar la senda de vida de mujer combatiente.

No podría decirse a la luz del caleidoscopio de la vida de Ana María que ella haya sido tan solo la esposa o la compañera de Mario Roberto Santucho. Fue, si se siguen sus pistas, una activista que tempranamente, desde fines de los años `50, y en el noreste del país, articuló de manera sensible su actuación política entre los indígenas, los obreros y los combatientes, intentando cumplir los mandatos revolucionarios, incluyendo en ellos sus vínculos familiares y amorosos.

\section{Exequias y honras a una Crista guerrillera}

Distintas memorias sociales patagónicas aseguran que Ana asesinó a Juan Gregorio Valenzuela, el guardia cárcel que cayó muerto en la fuga de la cárcel de Rawson. En el diario "Jornada" del 16 de agosto de 2019 se publicó un artículo titulado: "Acto por Juan Valenzuela. Era guardia cárcel y fue muerto el 15 de agosto de 1972”. En él se incluía el testimonio de sus hijas donde explicaban que "Valenzuela tardó en reconocer que los que venían hacia él no eran sus compañeros. Cuando lo hizo dio la voz de alto pero los guerrilleros le pidieron que se entregue. Se tocó la cartuchera, pero no tenía la pistola”. Cuando la buscó sobre la mesa fue tarde para defenderse y una ráfaga lo acribilló. "Tenía el cinturón como un colador", aseguran. Esta versión asevera que Ana María Villarreal de Santucho 
se iba de la cárcel, pero decidió volver sobre sus pasos y remató a

Valenzuela en la cabeza con 13 disparos más un tiro de gracia. La descripción del evento y sus protagonistas se basaba en un relato que les brindó Justino Galarraga, otro guardia cárcel a quien Mirta, hija de Valenzuela, había ido a ver a Misiones. ${ }^{30}$

Esta memoria, aun cuando no resiste validación alguna, ha sido repetida incansablemente, lo cual supone la adjudicación de una responsabilidad a partir de un gran índice de rencor y resentimiento hacia Ana María Villarreal. Sin dudas, las inculpaciones se acrecientan por su condición de mujer, de madre, por estar embarazada, por desafiar a las instituciones, a las tradiciones y al sentido común hegemónico, y por tomar las armas para ir tras sus objetivos. La responsabilidad de Marcos Osantinsky por la muerte del guardia cárcel no ha disipado la culpa de Ana por esta ejecución.

Para comprender las circunstancias y el tipo de violencia que continuó ejerciéndose brutalmente sobre su memoria desde el Estado, es necesario señalar que, aunque recibiría por parte de la militancia de izquierda honras fúnebres junto a María Angélica Sabelli y Eduardo Capello - integrantes de las FAR y del ERP respectivamente-, su cuerpo llegó a la sede central del Partido Justicialista donde se preparaba el velatorio colectivo muchas horas después de iniciado el mismo.

En medio de una serie de maniobras amedrentadoras y provocativas, las fuerzas de seguridad recomendaron a los familiares que actuaran con discreción y privacidad, prohibiéndoles la apertura de los ataúdes. El informe elaborado por el Foro de Buenos Aires por la vigencia de los Derechos Humanos (1973:74-75) detalló sin embargo que, ante un local colmado de personas, se tomó la decisión de reconocer los cuerpos y de consignar las heridas de Eduardo Capello y de María Angélica Sabelli. Pero esto no sucedió con el cuerpo de Ana.

Mientras la ceremonia se desarrollaba con la participación de monseñor Jerónimo Podestá y de los sacerdotes Carlos Mugica y Alberto Carbone, la policía montada a caballo irrumpió y derribó el portón, desatando una feroz represión contra las personas presentes. La orden fue impartida por el comisario Alberto Villar quien estaba bajo la égida del jefe del I Cuerpo de Ejército, Tomás Sánchez de Bustamante. Con un despliegue represivo espectacular que incluyó lanza gases, carros hidrantes, carros de asalto, motos, perros, patrulleros, tanquetas y autos camuflados, se dio por concluido el velatorio, advirtiendo que no se toleraría ninguna manifestación fúnebre. Mientras se avanzaba contra la multitud

30 Diario Jornada. Disponible en:

https://www.diariojornada.com.ar/252394/sociedad/acto_por_juan_valenzuela/. Última entrada $7 \mathrm{de}$ agosto de 2020 
violentamente, se trasladaron en una ambulancia los restos de los cuerpos a distintos lugares. María Angélica y Eduardo fueron enterrados en el cementerio de la Chacarita, en medio de un operativo policial que impidió que sus familiares pudiesen acercarse a las fosas para darles el saludo final. Entre tanto, a Ana la sepultaron en el cementerio de Boulogne, a $26 \mathrm{~km}$ de la capital metropolitana. ${ }^{31} \mathrm{En}$ la prueba documental obrante en la causa conocida como Masacre de Trelew, se presentó un comunicado del Comando del Primer Cuerpo de Ejército que informaba a la opinión pública lo siguiente:

\begin{abstract}
"Previo acuerdo de este Comando con los familiares de los fallecidos Maria Sabelli, Ana Maria Villarreal de Santucho y Eduardo Capello, se resolvió que en la fecha 24 de agosto de 1972, se llevaron a cabo los sepelios correspondientes. Los mismos se efectuaron conforme a lo dispuesto en los cementerios de Chacarita y Boulogne. Dicha resolución obedeció a la idea de llevar a cabo los actos de inhumación con la mayor celeridad posible, evitando las alteraciones de orden público buscadas por sectores interesados, a través de gestiones oficiales y sugerencias partidarias sobre los familiares de los fallecidos" (Causa $N^{\circ} 12-F^{\circ} 122$, subrayado nuestro).
\end{abstract}

En este escrito se hace referencia a un acuerdo que no existió. Por el contrario, tanto el velatorio como la inhumación de los cuerpos estuvieron plagados de actos intimidatorios violentos a nivel material y simbólico. Solo el tesón de las gestiones de Edmundo Villarreal, su padre, logró que los restos de Ana fueran trasladados a Salta. En su tumba, un epitafio cariñoso la acompañó un tiempo: Tu esposo e hijitas, padres, hermanos, familiares y compañeros. Quienes cuidan el sitio donde descansan sus restos han denunciado diversos actos de profanación en su lápida.

Los vínculos simbólicos que Sayo entabló con el mundo andino, sea a partir de la identificación con el FRIP o por su particular sensibilidad y cercanía con el arte popular latinoamericano, emergen y cristalizan en los múltiples sentidos que sugiere la escultura "El Cristo Guerrillero". Esta obra de Edmundo Diego Villarreal fue cincelada en el año 1973 y donada por él a la iglesia de Tilcara, en la provincia de Jujuy. En ese Cristo de más de un metro de altura, don Edmundo talló las balas que asesinaron a su hija.

Vale la pena situar y problematizar simultáneamente esta obra íntima porque el gesto performático de este escultor ha implicado otras veneraciones propias de la Quebrada de Humahuaca. De las tensiones que se han sucedido entre los fieles de la comunidad de Tilcara y los fieles de Tumbaya se debe señalar que las mismas fueron por momentos inconciliables. En 1961, a instancias del párroco de la primera localidad, la elite pueblerina, representada por las damas de las instituciones religiosas y cofradias, argumentó en favor de la oposición a las tradiciones locales de fusión de la imaginería católica con tradiciones ancestrales de

${ }^{31}$ Diario Crónica, 25 de agosto de 1972. 
campesinos y obreros. Operando una constante minusvaloración de la fe popular, tuvo lugar entonces una fuerte tensión entre la Iglesia y las poblaciones andinas que defendian sus costumbres religiosas, muy enfáticamente desde 1955, año en que se produjo el derrocamiento del peronismo y que tuvo en Tilcara también hitos muy violentos (Farrell 1976: 119, citado por Gudemus, 2015: 504). En 1972 se planteó una nueva disputa en torno a la imagen de la Virgen de Copacabana de Punta Corral entre las dos poblaciones, lo que hizo que los tilcareños buscaran finalmente rescatarla. Pero mediante un litigio judicial y eclesiástico, y al amparo del derecho de propiedad privada, la imagen religiosa volvió a la localidad de Tumbaya. Fue en este contexto que desde Tilcara se entronizó en la capilla de Punta Corral "El Cristo Guerrillero" de tallado por Edmundo Villarreal. Con un rostro delicado donde destacaban los ojos rasgados, la memoria popular da cuenta del testimonio y la denuncia que el artista plasmó al imprimir a su obra no sólo las cicatrices de los clavos, sino también las de los disparos en el cuerpo de su hija (Gudemus, 2015: 506). Al momento de realizarse la ceremonia de traslado del Cristo en la Semana Santa de 1973, y ante la sorpresa de la multitud, las fuerzas de seguridad -tanto del Ejército como de Policia- trataron de impedir su consagración. Sin embargo, la población se interpuso, “(...) era una pieza de arte, un objeto que fue hecho por encargo, pero que comenzaba a concentrar fuerzas y que, ya desde un inicio, ponía cualidades nuevas al espacio preexistente" (Molinari, 2004:20).

Desde siempre el "Cristo Guerrillero" tuvo carácter insurgente. Fue proscrito por las autoridades politicas con la anuencia de las eclesiásticas, y protegido, transportado, y honrado en la clandestinidad por distintas gentes del pueblo. En los últimos días de abril de 1995 fue decapitado y ultrajado ya que un grupo de personas, aún no identificadas, subieron al elevado santuario de la Virgen de Copacabana del Abra de Punta Corral y destrozaron la escultura a martillazos. Sólo un brazo quedó fijado a la cruz. Luego se arrastró el cuerpo sin poder partirlo, pero lograron separar las extremidades e hicieron desaparecer la cabeza, abandonando la corona de espinas. De acuerdo a los registros obtenidos en la conmemoración de 1996, los vecinos tilcareños, que se asentaban próximos al puente del río Guasamayo, interpretaron este descuartizamiento como un "mensaje antisubversivo". Incluso hubo quienes entendieron en estos hechos una "nueva ejecución" del líder indígena anticolonial, Túpac Amaru, con las connotaciones ideológicas del caso (Gudemus, 2015:507). 
Imagen 2: Restos de "El Cristo Guerrillero", escultura de Edmundo Villarreal realizada en 1973 y destruida en 1995.

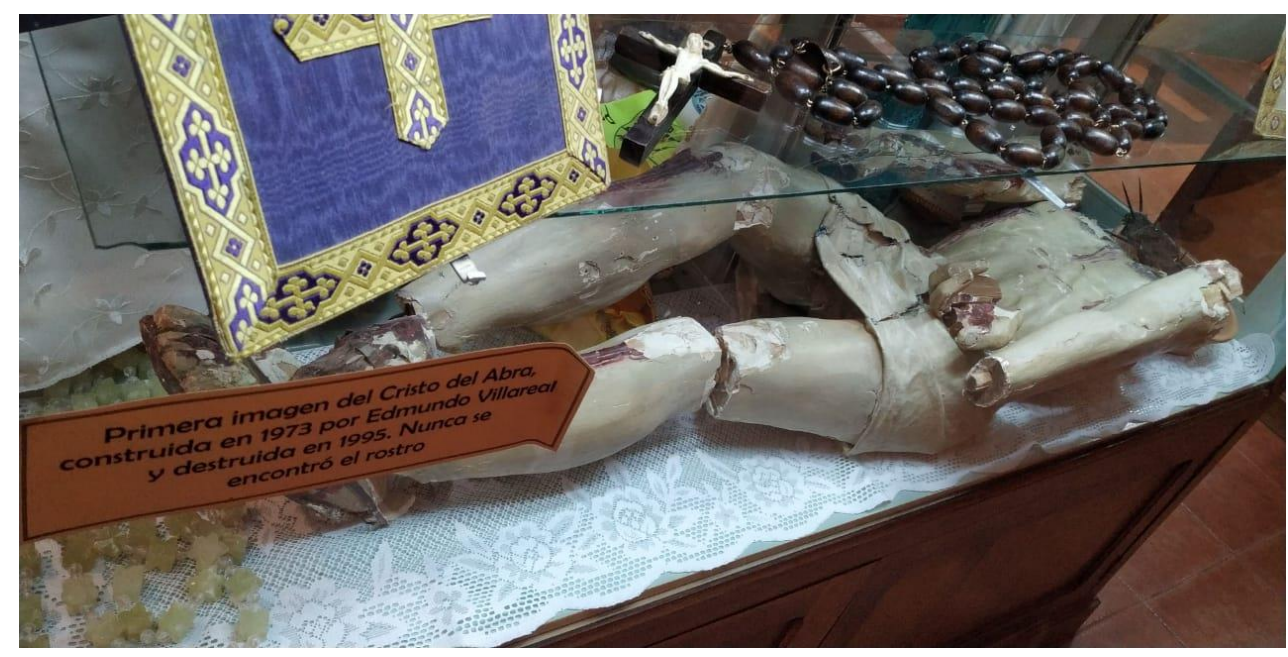

Fuente: archivo de las autoras

Los restos de la escultura quebrada permanecieron en la Iglesia del Rosario, en Tilcara, en una urna de vidrio para ser preservados y a la vez expuestos. Pero en el año 2003, por decisión eclesiástica, fueron depositados debajo de una mesa y cubiertos con un lienzo. Según entiende sobre este punto el investigador en Artes Visuales, Eduardo Molinari, "el Cristo partido permanece invisible, sustraído a la mirada de los habitantes y visitantes" (Molinari, 2004:21). Casi, casi como Ana María Villarreal, cuyos pasos hemos tratado de reconstruir en estas páginas. Mas, ¿cómo obviar la inscripción de cada uno de estos avatares en la historia argentina? La inspiración del "Cristo Guerrillero" fue la masacre de 1972 en la ciudad de Trelew en la que el Estado fusiló a 16 militantes revolucionarios. Mario Santucho, hijo de Roby y de su nueva pareja Liliana Delfino, refirió a la escultura del "Cristo Guerrillero" como una "imagen hecha de otro material" cuya profanación fue en definitiva, un nuevo acto de violencia ejercido contra Sayo en continuidad con su ejecución y la represión desatada durante los velatorios-homenajes a las personas ejecutadas en Trelew (Molinari, 2004:33)

\section{Algunas reflexiones finales}

Ahondar en la vida de Ana María Villareal de Santucho nos permitió colocar en el centro de las preocupaciones las preguntas por la investigación histórica de la historia de las mujeres y los estudios de género. No se trata de inquirir si la información existente puede ser exigua sino en qué medida el género como registro histórico permite pensar lo colectivo de la vida de las mujeres y jerarquizar unos

\section{anuario.}


fragmentos que se presentan dispersos. Ese itinerario personal queda en este ejercicio historiográfico enmarcado en tramas más amplias, relacionales y generizadas de la participación temprana de las mujeres en la vida política de nuestro país. La ponderación de la palabra de sus compañeras y compañeros de militancia -muchas veces esquiva- y la de sus familiares no tiene por finalidad complementar el rol de quienes sí hicieron Historia, los líderes varones, en este caso el de su compañero Mario Roberto Santucho. Nos remitimos por el contrario al valor histórico en sí mismo que comporta la reconstrucción de la vida de Ana María Villarreal. Nuestra pretensión fue la de brindar un conjunto de pistas que permitieran superar la narrativa biográfica sostenida en los hechos como única variable explicativa del pasado para enlazarla con otras dimensiones interpretativas, como las que proporcionan los registros memoriales de quienes estuvieron cerca de ella. Esos registros nos ayudaron a recuperar su figura humanizándola y viendo distintas aristas de su activismo de modo generizado. Así, pudimos advertirla en lugares diversos y bajo registros variados. No fue solo la guerrillera, la "subversiva" tal como era nombrada por la prensa de la época, la fugada y condenada a prisión de máxima seguridad, o la víctima de los fusilamientos de Trelew. Tampoco fue solo la esposa de Mario Roberto Santucho, la madre de Ana, Marcela y Gabriela, la hija de don Edmundo o la hermana de Cristina. Tal vez, y de hecho, Ana María o Sayo fueron todo eso y más. Fue la joven que estudió Artes Plásticas esforzándose por vivir en Tucumán. Fue la que aprendió a bailar zamba y cueca mientras dibujaba alimentando una sensibilidad que luego la emparentaría con los sueños revolucionarios, aunque ella aún no lo supiese. Fue la que siguió sus propias huellas recorriendo los senderos latinoamericanos que otros y otras habian pisado antes que ella, buscando los fulgores emancipatorios. Fue la que entró, junto a su compañero, a esa Habana recientemente triunfante a encontrarse con una revolución que inspiraría y alentaría a tantos otros y otras años más tarde. Fue la que repartía alimentos en un barrio marginal y se tiroteaba con la policía acudiendo a los hechos con otro nombre. También, la que se enojó con Clarisa y Roby por sus amores a cubierto y descubiertos. Además, fue quien enseñó a leer y a escribir a los que cosechaban y molían la caña de azúcar, y la amiga de sus amigas. Sayo fue una mujer con múltiples facetas, dueña de una trayectoria política propia y autónoma que fue cultivando desde los tempranos momentos de militancia comprometida con el FRIP, pasando por la fundación del PRT y del ERP, y en el centelleo político de los primeros años setenta.

Este conjunto de afirmaciones recupera una masa critica y significativa de trabajos que vienen indagando en la participación política de las mujeres en el pasado reciente, ocupándose de mostrar los límites de un relato historiográfico sostenido en la universalización masculina de su discurrir. Al colocar el análisis sexuado en el centro de la comprensión de ese pasado, estos trabajos han enriquecido su tratamiento ampliando las dimensiones históricas en juego, los sujetos que fueron 
parte activa de ese proceso, las diversas territorialidades en las que ese pasado cobró existencia.

La biografia de Sayo es parte de esas renovaciones del relato histórico y ofrece anclaje empírico a una importante cantidad de ideas existentes sobre el período. De tal modo, retomamos este género omo un ejercicio para ir más allá del clásico registro de la vida de los "grandes hombres", pero también del de las "mujeres excepcionales". Su historia contribuye de forma singular a narrar la historia de toda una generación de mujeres que encuentran nexos entre lo político y lo personal.

En ese sentido, la historia de esta militante revolucionaria se vuelve también una excusa para expandir los relatos existentes sobre el pasado reciente y para repensar las dinámicas más generales de este período histórico. Así, hurgar en su vida, por ejemplo, hace visibles otras genealogias de la militancia setentista al denotar el temprano ingreso de las mujeres en ella. Posibilita advertir la participación activa de las provincias no metropolitanas en ese proceso, con problemáticas incluso novedosas como la del indigenismo que promovía el FRIP, donde Sayo estuvo efectivamente implicada. En esas provincias, los limites del mercado de trabajo se vieron ensanchados por una presencia femenina que vio en las universidades otros destinos posibles y ajenos al ideal de la domesticidad, que también fue con mayor o menor prestancia y consistencia, sometido a debate.

Asimismo, su decisión de formar parte de organizaciones que cuestionaban el sistema capitalista acudiendo a la vía armada nos ayuda a entender por qué la agencia femenina de esos años impulsó al Estado a redefinir sus instituciones penales y penitenciarias. El activo protagonismo de estas mujeres militantes en desestabilizar las condiciones de seguridad de los presidios permite explicar el porqué de la decisión de secularización tardia de la administración del castigo femenino. Una generación de mujeres que fue colocada, con una magnitud hasta alli insospechada, en el centro de la agenda de la persecución política estatal, justamente por su repertorio de acciones novedosas y por la valía de esa nueva subjetividad. Reconsiderar las singularidades de esta agencia femenina redefine necesariamente el punto de vista para narrar el pasado histórico. De allí su importancia. 


\section{Bibliografia}

Andújar, A. (2009). El amor en tiempos de revolución: los vínculos de pareja en la militancia de los 70. Batallas, telenovelas y rock and roll. En Andújar, A. et al. (ed.) De minifaldas, militancias y revoluciones. Exploraciones sobre los '70 en Argentina. Buenos Aires: Ediciones Luxemburg.

Andújar, A. (2014). Rutas argentinas hasta el fin. Mujeres, politica y piquetes, 1996-2001. Buenos Aires: Ediciones Luxemburg.

Andújar, A. et al. (2009). De minifaldas, militancias y revoluciones. Exploraciones sobre los '70 en Argentina. Buenos Aires: Ediciones Luxemburg.

Andújar, A. et al. (2010). Hilvanando historias. Mujeres y politica en el pasado reciente latinoamericano. Buenos Aires: Ediciones Luxemburg-IIEGE.

Barrancos, D. (2007). Mujeres en la sociedad argentina. Una historia de cinco siglos. Buenos Aires: Sudamericana.

Chama, M. (2000). Compromiso político y práctica profesional a principios de los setenta: El caso de Asociación Gremial de Abogados, Sociohistórica, (7). Recuperado

http://www.fuentesmemoria.fahce.unlp.edu.ar/art_revistas/pr.2821/pr. 2821.pdf

Cosse, I. (2010). Pareja, sexualidad y familia en los años sesenta. Una revolución discreta en Buenos Aires. Buenos Aires: Siglo XXI Editores.

Cosse, I. (2014), Mafalda. Historia social y politica. Buenos Aires: Fondo de Cultura Económica.

Cosse, I. (2017). "Infidelidades": moral, revolución y sexualidad en las organizaciones de la izquierda armada en la Argentina de los años 70. Prácticas de Oficio, v. 1, n. 19, jun-dic. Recuperado de: www. ides.org.ar/publicaciones/practicasdeoficio.

D`Antonio, D. (2009). "Rejas, gritos, cadenas, ruidos, ollas". La agencia política en las cárceles del Estado terrorista en Argentina, 1974-1983. En Andújar, A. et al. (ed.). De minifaldas, militancias y revoluciones. Exploraciones sobre los 70 en la Argentina. Buenos Aires: Ediciones Luxemburg. 
D`Antonio, D. (2013). Presas políticas y prácticas de control social estatal en la Argentina durante los años setenta. Revista Contemporánea, Historia y problemas del Siglo XX. Universidad de la República, Montevideo, No 4, Vol. 4.

D`Antonio, D. (2016). La prisión en los años setenta: Historia, género y política. Buenos Aires: Biblos.

D`Antonio, D. y Viano, C. (2018). A propósito de la historia reciente, la historia de las mujeres y los estudios de género: intersecciones y desafios. En Águila, G. et al, La historia reciente en Argentina. Balances de una historiografia pionera en América Latina. Buenos Aires: Imago Mundi.

Gatica, M. (1997). Formación, burocratización y proyección de un gremio. El caso SITRAVICH 1972-1984. Informe Final, SCyT, Comodoro Rivadavia 1997.

Gatica, M. (2007). Hacedores de Caminos. El sindicato de trabajadores viales de Chubut. Buenos Aires, Imago Mundi.

Grammático, K. (2005). Las 'mujeres políticas' y las feministas en los tempranos setenta: ¿un diálogo (im)posible? En Andújar, A. et al. (comps.). Historia, género y politica en los 70. Buenos Aires: Feminaria.

Grammático, K. (2011). Mujeres Montoneras. Una historia de la Agrupación Evita, 1973-1974. Buenos Aires: Ediciones Luxemburg.

Giusani, L. (2005). Buscada. Lili Massaferro: de los dorados años cincuenta a la militancia montonera. Buenos Aires: Norma.

Gudemus, M. (2015). Discursividades de una historia conflictiva. Espacio tiempo ceremonial de la Semana Santa y conflictos sociales emergentes en la Quebrada de Humahuaca (Noreste Argentino). Revista Española de Antropología Americana, Vol. 45, Nro.2.

James, D. (2004). Doña María Historia de vida, memoria e identidad politica. Buenos Aires: Manantial.

Jelin, E. (2002). Los trabajos de la memoria. Madrid: Siglo XXI Editores.

Lorenz, F. (2017). Cenizas que te rodearon al caer. Buenos Aires: Sudamericana.

Manzano, V. (2017). La era de la juventud en Argentina. Cultura, politica y sexualidad desde Perón a Videla. Buenos Aires: Fondo de Cultura Económica.

Martinez, P. (2009). Género, politica y revolución en los años '70. Las mujeres del PRT-ERP. Buenos Aires: Imago Mundi. 
Molinari, E. (2004). El libro plateado y real. Museum Ludwig: Colonia, Alemania.

Noguera, A. (2013). La participación de las mujeres en la lucha armada. Córdoba, Argentina, 1970-1973. En Taller. Revista de historia, cultural y sociedad, Vol $2 . \mathrm{N}^{\circ} 2$.

Noguera, A (2019). Revoltosas y revolucionarias. Mujeres y militancia en la Córdoba setentista. Córdoba: UNC.

Oberti, A. (2015). Las revolucionarias. Militancia, vida cotidiana y afectividad en los setenta. Buenos Aires: Edhasa.

Pasquali, L. (2008). Mandatos y voluntades: aspectos de la militancia de mujeres en la guerrilla. Temas de Mujeres. Año $4-\mathrm{N}^{\circ} 4$.

Plis Sterenberg, G. (2003). Monte Chingolo. La mayor batalla de la guerrilla argentina. Buenos Aires: Planeta.

Portelli, A. (2003-2004). El uso de la entrevista en la historia oral. Anuario Historia, memoria y pasado reciente. Rosario: Escuela de Historia-UNR/Homo Sapiens, $N^{\circ} 20$.

Portelli, A. (2016). Historias orales. Narración, imaginación y diálogo. Rosario: Prohistoria Ediciones.

Pozzi, P. (2001). Por las sendas argentinas... El PRT-ERP. La guerrilla marxista. Buenos Aires: EUDEBA.

Saidón, G. (2005). La montonera. Buenos Aires: Sudamericana.

Schwarzstein, D. (comp.) (2001). La historia oral. Buenos Aires: CEAL.

Seoane, M. (2014). Bravas. Alicia Eguren de Cooke y Susana Pirí Lugones. Dos mujeres para una pasión argentina. Buenos Aires: Sudamericana.

Seminara, L. (2015). Bajo la sombra del ombú. Montoneros Sabino Navarro, historia de una disidencia. Buenos Aires: Imago Mundi.

Tarcus, H. (2007). Diccionario biográfico de la izquierda argentina. De los anarquistas a la nueva izquierda (1870-1976). Buenos Aires: EMECE. 
Thompson, P. (2003-2004). Historia oral y contemporaneidad. Anuario Historia, memoria y pasado reciente (Rosario: Escuela de Historia-UNR/Homo Sapiens, No 20.

Vassallo, A. (2005). 'Las mujeres dicen basta': movilización, política y orígenes del feminismo argentino en los 70. En Andújar, A. et al. (comps.), Historia, género y politica en los 70. Buenos Aires: Feminaria.

Viano, C. (2008). Mujeres y movimientos sociales: un acercamiento a Madres de Plaza de Mayo desde una historia de vida. En Necoechea Gracia, G. et al. Historia oral y militancia politica en México y en Argentina. Buenos Aires: E1 Colectivo/FFyL-UBA.

Viano, C. (2011). Pinceladas sobre las relaciones de género en la nueva izquierda peronista de los primeros años ${ }^{\top} 70$. Temas de mujeres, $\mathrm{N}^{\circ} 7$.

\section{Fuentes:}

Augier, Pola (2012) Jardines del Cielo. Experiencias de una guerrillera. Buenos Aires: Sudestada.

Santucho, Blanca Rina (2004). Nosotros, los Santucho. Buenos Aires: Nuestra América

De Santis, Daniel (2006), A Vencer o Morir PRT - ERP Documentos. Vol. 1 y 2. Buenos Aires: Eudeba

Diana, Marta (1996), Mujeres Guerrilleras. La militancia de los setenta en el testimonio de sus protagonistas femeninas (Buenos Aires, Ed. Planeta)

Genaro, Dora. Biografía. S/F

Santucho, Marcela (2008), Mario Roberto Santucho, Mi Padre el revolucionario. Buenos Aires: Dunken.

Entrevistas realizadas por las autoras entre junio y septiembre de 2018: Carlos González Gartland, Alicia Sanguinetti, Estela Aseff, Luis Lea Place, Abel Bohoslavsky y Pedro Cazes Camarero.

Recibido: 3 de febrero de 2021 Aceptado: 15 de marzo de 2021 Versión Final: 26 de marzo de 2021 